\title{
KERAGAMAN MIKOFLORA TANAH SUPRESIF DALAM MENGENDALIKAN PENYAKIT AKAR GADA PADA TANAMAN KUBIS (BRASSICA OLERACEA L.)
}

\author{
Ni Nengah Darmiati ${ }^{1)}$ dan I Made Sudarma ${ }^{1^{*}}$ \\ ${ }^{1)}$ Program Studi Agroekoteknologi, Fakultas Pertanian Universitas Udayana \\ *email: sudarma_made@ymail.com.
}

\begin{abstract}
Cabbage (Brassica oleracea L.) was a vegetable crops cultivated in the highlands to meet the needs of the community vegetable. The main obstacle was the cultivation of cabbage root disease outbreak mace (clubroot), which until now have not found an effective control techniques. Clubroot disease caused by organisms that resemble fungi: Plasmodiophora brassicae Wor. which was the soil inhibitant and soil borne pathogen. Therefore, there must be a way to control environmentally friendly by using suppressive soil, find microbes antagonists related to the cabbage plant habitat in the soil. The results showed that the index of diversity both on suppressive and conducive soil of 1.2304 and 1.2811 respectively, and the index of dominance on the suppressive and conducive soil were 0.6677 and 0.6838 . Prevalence micoflora of the suppressive soil amounted to $44.22 \%$ and $43.06 \%$ conducive soil all dominated by Fusarium spp. Microbial antagonist as a potential control of $P$. brassicae was Trichoderma sp. Based on the analysis in the suppressive soil as much as $171 \mathrm{x}$ $10^{3} \mathrm{cfu} / \mathrm{g}$ soil, higher than on the conducive soil to $90 \times 10^{3} \mathrm{cfu} / \mathrm{g}$ soil.
\end{abstract}

Keywords: Cabbage (Brassica oleracea L.), supperessive and condussive soil, Palmodiophora brassicae, prevalence, and soil inhibitant.

\section{PENDAHULUAN}

Tanaman kubis (Brassica oleracea L.) telah lama dibudidayakan sebagai tanaman sayuran dan merupakan sumber vitamin, mineral dan serat (Keinath et al., 2006). Di Bali tanaman kubis-kubisan banyak dibudidayakan didataran tinggi seperti Baturiti-Tabanan, Candikuning-Buleleng dan Kintamani-Bangli. Menurut Semangun (1989) tanaman kubis-kubisan yang ditanam sekarang ini telah menderita penyakit akar gada (clubroot) yang disebabkan oleh jamur Plasmodiophora brassicae Wor.). Kerugian yang disebabkan oleh penyakit akar gada pada tanaman kubis-kubisan di Inggris, Jerman, Amerika Serikat, Asia dan Afrika Selatan mencapai 50-100\%. Di Australia patogen ini menyebabkan kehilangan hasil sekitar 10\% setiap tahun dengan kehilangan pendapatan sebesar US\$ 13 juta. Di Indonesia penyakit ini menyebabkan kerusakan pada kubis-kubisan sekitar $88,60 \%$ dan pada tanaman caisin sekitar 5,42-64,81\% (Cicu, 2006).Usaha pengendalian terhadap penyakit akar gada membutuhkan cara alternatif lain yang ramah lingkungan, efisien dan efektif dibandingkan yang hanya bertumpu pada pestisida sintetis. Untuk itu pemanfaatan tanah supresif dengan peran mikroba yang adadi dalamnya diharapkan lebih menjanjikan untuk mengendalikan penyakit ini (Garbeva et al., 2004). Mikroba di dalam tanah jumlah dan jenisnya sangat banyak, tergantung tingkat kesuburan tanah.
Conklin (2008) menyatakan dalam satu gram tanah terdapat bakteri 108-109 jenis. actinomycetes 107 108 jenis per gram tanah, jamur terdapat 105-106 propagul per gram tanah. Mikroba ini (bakteri, actinomycetes dan jamur) jumlahnya cukup besar dalam tanah. Kalia dan Gupta (2005) menyatakan bahwa perlu langkah konservasi apabila telah mengetahui kegunaan dari keragaman mikroba seperti : berperanan dalam biogeochemical dalam siklus nutrisi, penggunaan lahan berkelanjutan, produk mikroba untuk pertanian, biodegradasi dari xenobiotik dan pemanfaatan untuk industri.

\section{METODOLOGI}

\subsection{Tempat dan Waktu Penelitian}

Penelitian dilaksanakan di dua tempat di lapangan yaitu disentar produksi kubis Bali yakni di Candi Kuning, tabanan dan Panca Sari, Buleleng. Penelitian dilaksanakan dari bulan Maret sampai dengan Juni 2015. Setelah sampel diperoleh dilanjutkan dengan analisis mikroba tanah di laoratorium Ilmu Penyakit Tumbuhan fakultas Pertanian Universitas Udayana.

\subsection{Penelitian di Lapangan}

Sampel tanah diperoleh dari habitat rizosfer tanaman kubis sakit dan sehat yang diambil dari di areal sentra tanaman kubis di sentra produksi kubis 
Bali. Tanaman kubis yang sakit diamati, banyaknya rumpun, jumlah tanaman sakit, sehingga dapat ditentukan serangan penyakit dengan menggunakan rumus yakni : jumlah tanaman sakit dibagi dengan seluruh tanaman yang diamati kali 100\%. Pengambilan data tanah diambil berdasarkan hasil survei pada sentra tanaman sehat dan sakit dengan mengambil tanah di dekat perakaran tanaman kubis sehat dan sakit dengan kedalam kurang lebih $20 \mathrm{~cm}$ masing-masing sebanyak 100 gram, setiap tanaman diambil 4 kali kemudian dicampur merata.

\subsection{Penelitian di Laboratorium}

A. Menentukan Populasi Mikoflora Tanah

Tanah sampel satu gram dilarutkan dalam air steril kemudian dicampur dan divortek. Suspensi tanah diencerkan sampai mencapai volume $10 \mathrm{ml}$. Pengenceran bertingkat dilakukan $10^{-2}-10^{-7}$ di bawah kondisi steril. Suspensi diambil $1 \mathrm{ml}$ dituangkan ke dalam piring Petri bersama dengan media biakan Media potato dextrose agar (PDA) dengan campuran kentang 200 g, gula 15 g, agar 20 g dalam aquades $1000 \mathrm{ml}$ dan livoplosaxin (antibiotik antibakteri) dengan konsentrasi $0,1 \%(\mathrm{w} / \mathrm{v})$ digunakan untuk isolasi jamur. Lima cawan Petri disiapkan untuk setiap larutan. Biakan diinkubasi pada ruang gelap pada suhu $27 \pm 2^{\circ} \mathrm{C}$, selanjutnya koloni dihitung sebagai colony forming unit (CFU). Koloni tunggal dipindahkan ke dalam cawan Petri baru yang berisi media PDA dan diikubasi pada suhu kamar. Isolat diidentifikasi secara makroskopis setelah berumur 3 hari untuk mengetahui warna koloni dan laju pertumbuhan, dan identifikasi secara mikroskopis untuk mengetahui septa pada hifa, bentuk spora/konidia dan sporangiofor (Samson et al., 1981; Pitt dan Hocking, 1997; Barnett dan Hunter, 1998; Indrawati et al., 1999).

B. Menentukan Indek Keragaman dan Dominasi Mikroba Tanah

Keragaman dan dominasi mikroba tanah dapat diketahui dengan menghitung indek keragaman Shannon-Wiener (Odum, 1971) dan dominasi mikroba tanah dihitung dengan menghitung indeks Simpson (Pirzan dan Pong-Masak, 2008).

\section{1) Indek keragaman mikroba}

Indek keragaman mikroba tanah ditentukan dengan indek keragaman Shannon-Wiener yaitu dengan rumus (Odum, 1971):

$$
H^{\prime}=-\sum_{i=1}^{S} P i \ln P i
$$

Keterangan:

$\mathrm{H}^{\prime}=$ indek keragaman Shannon-Wiener

$\mathrm{S}=$ Jumlah genus
$\mathrm{Pi}=$ ni/N sebagai proporsi jenis ke $\mathrm{i}$

(ni = Jumlah total individu jenis mikroba total i,

$\mathrm{N}=$ Jumlah seluruh individu dalam total $\mathrm{n}$ )

Kriteria yang digunakan untuk menginterprestasikan keragaman Shannon-Wiener (Ferianita-Fachrul et al., 2005) yakni: H'nilainya $<1$, berarti keragaman rendah, H' nilainya $1-$ 3 berarti keragaman tergolong sedang dan H' nilainya $>3$ berarti keragaman tergolong tinggi.

\section{2) Indek dominasi}

Indek dominasi mikroba tanah dihitung dengan menghitung indeks Simpson (Pirzan dan Pong-Masak, 2008), dengan rumus sebagai berikut : $\mathrm{S} \mathrm{C}=$ " $P i^{2} \mathrm{i}=1$ Keterangan : $\mathrm{C}=$ indek Simpson $\mathrm{S}=$ Jumlah genus $\mathrm{Pi}=$ ni/ $\mathrm{N}$ yakni proporsi individu jenis i dan seluruh individu (ni = Jumlah total individu jenis i, $\mathrm{N}=$ Jumlah seluruh individu dalam total n) Selanjutnya indek dominasi spesies (D) dapat dihitung dengan formulasi 1- C (Rad et al.2009).

Kreteria yang digunakan untuk menginterprestasikan dominasi jenis mikroba tanah yakni: mendekati $0=$ indek rendah atau semakin rendah dominasi oleh satu spesies mikroba atau tidak terdapat spesies yang secara ekstrim mendominasi spesies lainnya, mendekati $1=$ indek besar atau cendrung didomnasi oleh beberapa spesies mikroba (Pirzan dan PongMasak, 2008).

\section{3) Analisis Chi kuadrat}

Keragaman mikroba tanah pada habitat tanaman kubis dengan dan tanpa gejala sakit lebih banyak atau sedikit dapat dibuktikan dengan menggunakan analisis Chi kuadrat $\left(\mathrm{X}^{2}\right)$, atau t test dengan rumus (Gomes dan Gomes, 2007; Sugiyono, 2009):

$$
X^{2}=\sum_{i=1 E}^{p}\left(\underline{n}_{i}=\underline{E}_{i}\right)^{2}
$$

Keterangan :

$p$ = banyaknya kelas

$\mathrm{n}_{\mathrm{i}}=$ banyaknya satuan yang diamati yang termasuk kelas i

$\mathrm{E}_{\mathrm{i}}=$ banyaknya satuan yang diharapkan termasuk ke dalam kelas i

Selanjutnya nilai Chi kuadrat hitung dibandingkan dengan Chi kuadrat tabel, bila Chi kuadrat hitung lebih kecil dari tabel, maka Ho diterima dan sebaliknya. 


\section{HASIL DAN PEMBAHASAN}

\subsection{Populasi Jamur Tanah}

Populasi jamur tanah di tiga lokasi baik di tanah supresif maupun pada tanah kondusif (Gambar 1) menunjukkan perbedaan yang sangat nyata. Pada lokasi I jumlah koloni yang dapat ditemukan pada tanah supresif sebanyak $22 \times 10^{3} \mathrm{cfu} / \mathrm{g}$ tanah, pada tanah kondusif sebanyak $10 \times 10^{3} \mathrm{cfu} / \mathrm{g}$ tanah, pada lokasi II tanah supresif sebanyak $90 \times 10^{3} \mathrm{cfu} / \mathrm{g}$ tanah dan tanah kondusif $49 \mathrm{cfu} / \mathrm{g}$ tanah, pada lokasi III pada tanah supresif sebanyak $75 \times 10^{3} \mathrm{cfu} / \mathrm{g}$ tanah, dan pada tanah kondusif sebanyak $40 \times 10^{3} \mathrm{cfu} / \mathrm{g}$ tanah (Gambar 2).

Hal ini menunjukkan bahwa pada tanah supresif terdapat banyak mikoflora tanah dibadingkan pada tanah kondusif. Berarti salah satu ada sebagai mikroga antagonis yang menekan perkembangan patogen penyebab penyakit akar gada di tiga lokasi tersebut. Tanah bagi patogen tanaman adalah sebuah rumah sakit, melalui pembatasan baik lamanya bertahan hidup ataupun pertumbuhan patogen. Setiap tanah diketahui menekan patogen atau penyakit. Tanah supresif sangat ditentukan oleh keragaman mikroba tanah, sedangkan keragaman mikroba tanah dipengaruhi oleh tiga hal utama: (a) tipe tanaman yang merupakan penentu utama struktur dari komunitas mikroba dalam tanah, seperti tanaman penyedia utama karbon dan sumber energi, (b) tipe tanah merupakan penentu utama komunitas mikroba, sperti kombinasi struktur dan tekstur tanah, bahan organik, stabilitas mikroagregat, $\mathrm{pH}$, dan keberadaan hara kunci seperti N, P, dan Fe menetukan habitat dalam tanah, dan (c) cara mengelola pertanian yakni rotasi tanaman, pengelohan tanah, herbisida, aplikasi pemupukan dan irigasi juga menentukan struktur komunitas mikroba tanah (Nannipieri, et al., 2003; Garbeva et al., 2004).

Berdasarkan pengamatan selama penelitian ditemukan hanya 7 spesies jamur yang mengkolonisasi habitat tanah supresif maupun tanah
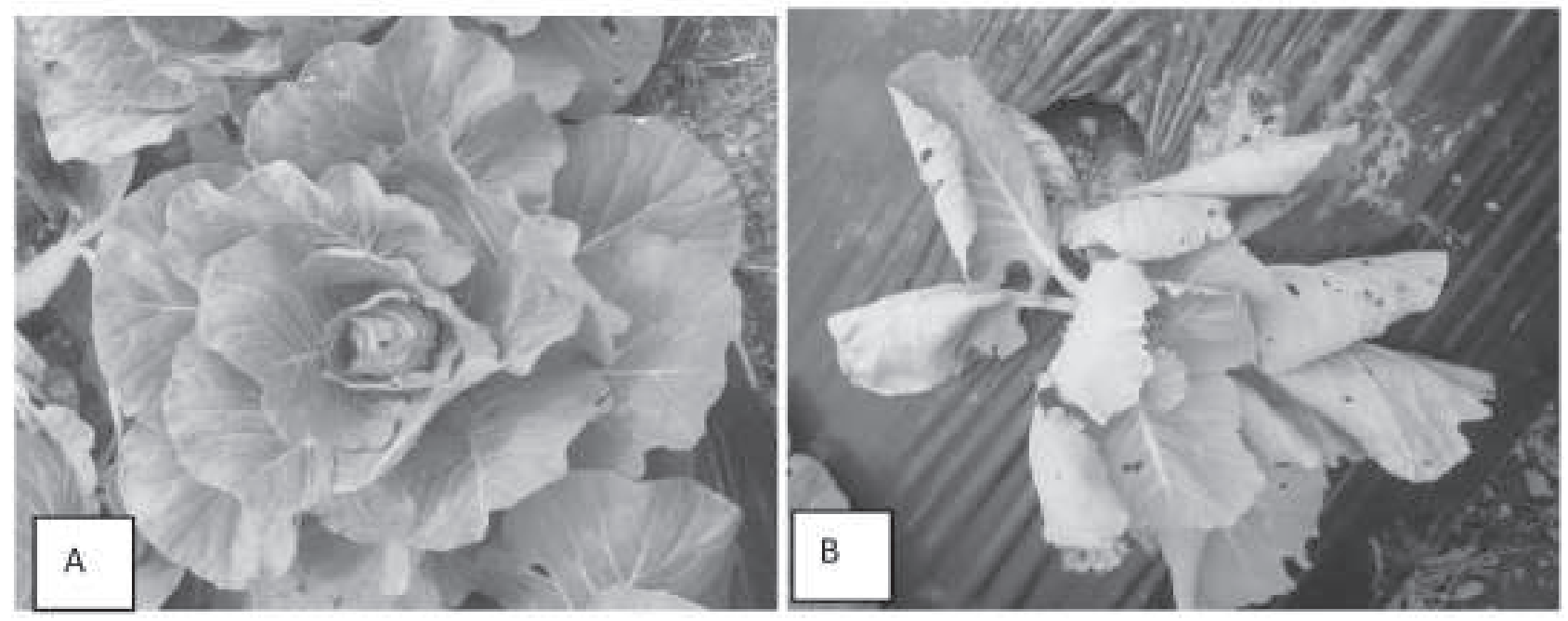

Gambar 1. Perbedaan tanah supresif (A) dan kondusif (B) yang ditanami kubis (sumber: dokumen pribadi)

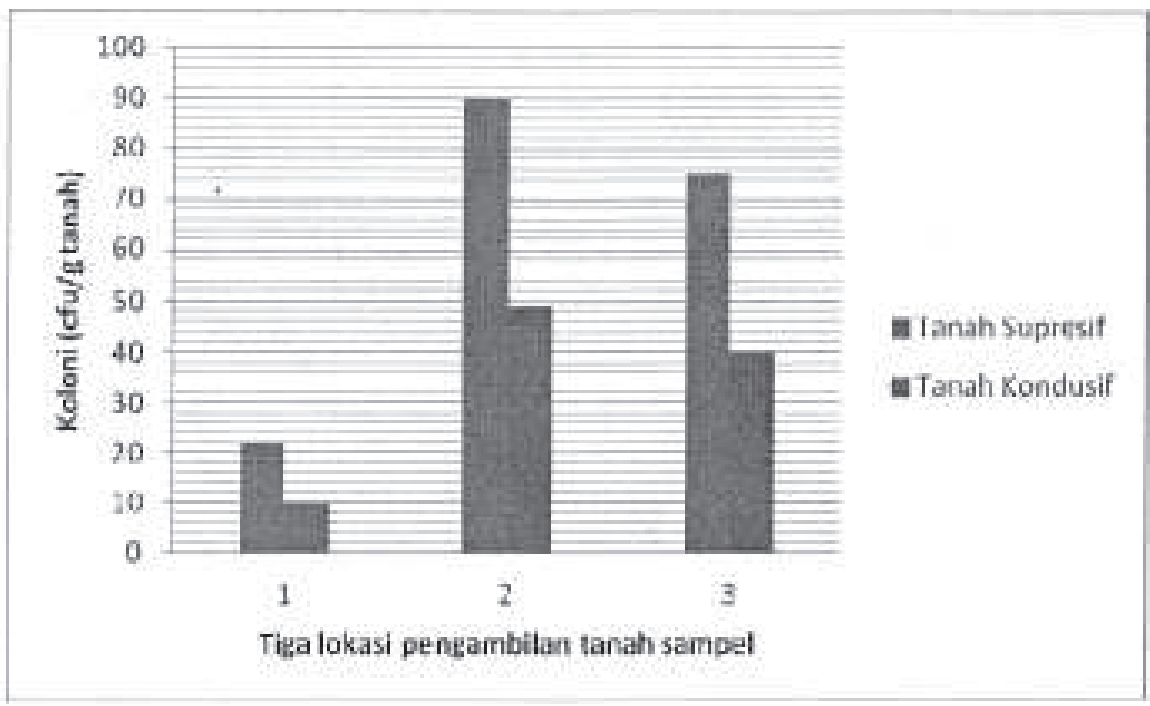

Gambar 2. Jumlah koloni mikoflora tanah pada tanah supresif dan tanah kondusif 
kondusif. Ketujuh jamur tersebut antara lain: Aspergillus spp., Aspergillus flavus, Aspergillus niger, Fusarium spp., Penicillium spp., Rhizopus spp., dan Trichoiderma spp. (Tabel 1).

\subsection{Indek Keragaman, Dominasi dan Prevalensi Mikoflora Tanah Supresif dan Kondusif}

Indek keragaman pada tanah supresif 1,2304 dalam kreteria rendah, dengan indek dominasi sebesar 0,6677, prevalensi tertinggi ditemukan pada Fusarium spp. sebesar 44,22\%, sedangkan pada tanah kondusif indek keragaman mencapai 1,2811, dengan indek dominasi 0,6838. Prevalensi tertinggi dicapai oleh Fusarium spp. sebesar 43,06\%. Indek keragaman menunjukkan variasi mikoflora yang terdapat dalam habitat tanaman kubis di tiga lokasi. Indek keragaman 1,2304 dan 1,2811 menunjukkan indek yang rendah, yang ini diakibatkan ada dominasi dari mikoflora lainnya yakni dalam hal ini adalah Fusarium spp. sebesar 44,22\% dan 43,06\% (Tabel 1).

Rendahnya indek keragaman disebabkan oleh banyaknya jamur yang mendominasi pada tanah supresif maupun tanah kondusif, dalam hal ini adalah Fusarium spp., disamping Fusarium spp., ada juga jamur Trichoderma spp. yang mendominasi kedua pada tanah supresif sebesar 28,64. Trichoderma spp. dikenal sebagai jamur mikoparasit yang antagonis terhadap jamur lainnya dalam tanah
Ada beberapa mekanisme supresi biologi penyakit tumbuhan meliputi: (1) antagonisme, kemampuan dari mikroba spesifik yang menguntungkan untuk menghasilkan antibiotic yang dapat membunuh organism petogen, (2) kompetisi untuk nutrisi dan energy, yakni pada beberapa kasus organisme patogenik adalah competitor yang jelek dalam hubungannya dengan mikroba yang menguntungkan. Dalam nutrisi dan energy yang terlibat dalam substrat, (3) kompetisi untuk kolonisasi akar, hal ini berhubungan dengan penyakit akar. Beberapa mikroba berguna memeiliki kemampuan untuk mengadakan kolonisasi pada akar tanaman sebelumpatogen dapat menginfeksi, sehingga akar terlindungi, (4) induced systemic resistence (ISR) atau systemic acquired resistence (SAR), adalah sebuah mekanisme dimana gen supresif aktif bekerja untuk menghadap patogen penyebab penyakit, gen tanaman yang menyandi senyawa ketahanan berkerja baik akibat rangsangan mikroba berguna maupun patogen penyebab penyakit (McKellar dan Nelson, 2003; Alexander, 2006; Singh dan Singh, 2008).

\subsection{Uji Antagonistik}

Hasil uji antagonistik (spora jamur Trichoderma sp. terhadap $P$. brassicae pada tanaman sawi putih) menunjukkan bahwa Trichoderma sp, dapat menekan pertumbuhan jamur patogen $P$. brassicae. Uji antagonistik dilakukan dengan cara mengamati

Tabel 1. Indek keragaman, dominasi dan prevalensi mikoflora tanah supresif dan kondusif

\begin{tabular}{|c|c|c|c|c|c|c|}
\hline \multirow[b]{2}{*}{ Nama jamur } & \multicolumn{3}{|c|}{ Tanah supresif } & \multicolumn{3}{|c|}{ Tanah kondusif } \\
\hline & $\begin{array}{c}\text { Populasi } \\
\left(x 10^{3} \mathrm{cfu} / \mathrm{g}\right)^{* *}\end{array}$ & $\begin{array}{c}\text { Prevalensi } \\
(\%)\end{array}$ & $\overline{\mathrm{H}^{\prime}}$ & $\begin{array}{l}\text { Populasi } \\
\text { (x103 cfu/g) }\end{array}$ & $\begin{array}{c}\text { Prevalensi } \\
(\%)\end{array}$ & $\overline{\mathrm{H}^{\prime}}$ \\
\hline Aspergillus spp. & 139 & 23,28 & & 122 & 28,71 & \\
\hline Aspergillus flavus & 2 & 0,34 & & 2 & 0,47 & \\
\hline Aspergillus niger & 3 & 0,50 & & 1 & 0,24 & \\
\hline Fusarium spp. & 264 & 44,22 & 1,2304 & 183 & 43,06 & 1,2811 \\
\hline Penicillium spp. & 9 & 1,51 & & 25 & 5,88 & \\
\hline Rhizopus spp. & 9 & 1,51 & & 2 & 0,47 & \\
\hline Trichoderma spp. & 171 & 28,64 & & 90 & 21,18 & \\
\hline Jumlah & 597 & & & 425 & & \\
\hline
\end{tabular}

**berbeda sangat nyata uji Chi kuadrat, $\mathrm{H}^{\prime}$ = indek keragaman

Tabel 2. Pengaruh pemberian spora jamur Trichoderma sp. sebagai jamur antagonsitik Plasmodiophora brassicae terhadap tinggi tanaman sawi putih

\begin{tabular}{lc}
\hline Perlakuan & Tinggi tanaman (cm) \\
\hline Tanpa Trichoderma sp. & $15,50 \mathrm{~d}$ \\
Pengenceran spora Trichoderma sp. $10 \mathrm{ml}\left(47,5 \times 10^{8} \mathrm{spora} / \mathrm{ml}\right)$ & $19,67 \mathrm{a}$ \\
Pengenceran spora Trichoderma sp. $30 \mathrm{ml}\left(136 \times 10^{7} \mathrm{spora} / \mathrm{ml}\right)$ & $18,37 \mathrm{~b}$ \\
Pengenceran spora Trichoderma sp. $50 \mathrm{ml}\left(95 \times 10^{7} \mathrm{spora} / \mathrm{ml}\right)$ & $17,73 \mathrm{c}$ \\
\hline
\end{tabular}

Keterangan: Angka yang diikuti oleh huruf yang sama pada kolom yang sama menunjukkan pengaruh yang tidak berbeda nyata pada uji BNT taraf $5 \%$ 
pertumbuhan tinggi tanaman sawi dari awal tanam sampai dengan tanaman kontrol menampakkan gejala akar gada. Hasil pengamatan uji antagonistik dapat dilihat pada Tabel 2.

Pertumbuhan tinggi tanaman sawi putih pada perlakuan dengan pemberian spora Trichoderma sp. $10 \mathrm{ml}$, menunjukkan pertumbuhan paling tinggi yaitu $19,67 \mathrm{~cm}$, dan pada perlakuan tanpa Trichoderma sp. menunjukkan pertumbuhan yang paling rendah yaitu 15,5 cm (Gambar 3). Dalam analisis statistika menunjukkan pengaruh pemberian spora jamur Trichoderma sp. nyata terhadap pertumbuhan tanaman sawi. Tanaman kubis tanpa perlakuan pertumbuhannya paling rendah karena adanya serangan jamur $P$. brassicae yang menyebabkan pertumbuhan tanaman sawi atau kubis menjadi kerdil dan merana, karena adanya pembengkakan pada sistem perakaran dari tanaman kubis.

\section{SIMPULAN DAN SARAN}

\subsection{Simpulan}

Berdasarkan hasil dan pembahasan dapat disimpulkan sebagai berikut: Indek keragaman baik pada tanah supresif maupun kondusif berturut sebesar 1,2304 dan 1,2811, dan indek dominasi pada tanah supresif dan kondusif berturut-turut sebesar 0,6677 dan 0,6838. Prevalensi mikoflora pada tanah supresif sebesar 44,22\% dan tanah kondusif 43,06\% semuanya dikuasai oleh Fusarium spp. Mikroba antagonis yang potensial sebagai pengendalikan $P$. brassicae adalah Trichoderma sp. Berdasarkan hasil analisis pada tanah supresif sebanyak 171 x $10^{3} \mathrm{cfu} /$ $\mathrm{g}$ tanah, lebih tinggi dibandingkan pada tanah kondusif sebanyak $90 \times 10^{3} \mathrm{cfu} / \mathrm{g}$ tanah. Hasil uji antagonistik dengan spora Ttrichoderma sp. menunjukkan hasil yang signifikan dalam mengendalikan penyakit akar gada yang telah diuji cobakan pada sawi putih.

\subsection{Saran}

Berdasarkan hasil dan pembahasan dapat disarankan sebagai berikut: Sebaiknya dilakukan analisis tanah untuk menentukan kandungan tekstur dan struktur tanah, biologi dan kimiawi tanah dalam mendukung data tanah supresif. Mengingat patogen bersifat obligat, jadi agak kesulitan dalam uji antagonistik secara buatan, sehingga diperlukan uji antagonistik langsung di lapangan.

\section{DAFTAR PUSTAKA}

Alexander, R. 2006. Compost and disease suppression, R. Alexander Assiciates, Inc., a Copmany specializing in organic recycled produkct and market development, 1-5 p.

Barnett, H.L. and B.B. Hunter. 1998. Illustrated Genera of Imperfect Fungi. APS Press. The American Phytopathological Sociey. St Paul, Minnesota. Pp. 218.

Cicu. 2006. Penyakit akar gada (Plasmodiphora brassicae Wor.) pada tanaman kubis-kubisan dan upaya pengendaliannya. Jurnal Litbang Pertanian, 25(1): 16-21.

Conklin, A.R. 2002. Soil Microorganisms. Soil Sediment and Water. Http://www.aehsmag.com/ issues/2002/januray/microorganisms.htm. AEHS Magazine. Disitir tanggal 10 Oktober 2008. $2 \mathrm{~h}$.

Ferianita-Fachrul, M., H. Haeruman, dan L.C. Sitepu. 2005. Komunitas Fitoplankton Sebagai Bio-Indikator Kualitas Perairan Teluk Jakarta. FMIPA-Universitas Indonesia Depok.

Garbeva, P., J.A. van Veen and J.D. van Elas. 2004. Microbial diversity in soil: selection of microbial population by plant and soil type and implications for disease suppressiveness. Annu. Rev. Phytopathol. 42: 243-270.

Gomes, K.A. dan A.A. Gomes, 2007. Prosedur Statistik untuk Penelitian Pertanian. Edisi kedua. Penerbit Universitas Indonesia (UIPress).

Indrawati. G., R.A. Samson, K. Van den TweelVermeulen, A. Oetari dan I. Santoso. 1999. Pengenalan Kapang Tropik Umum. Yayasan Obor Indonesia. Universitas Indonesia (University of Indonsia Culture Collection) Depok, Indonsia dan Centraalbureau voor Schirmmelcultures, Baarn, The Netherlands.

Kalia, A. And R.P. Gupta. 2005. Conservation and Utilization of Microbial Diversity. NBA Scientific Bulletin Number-1. National Biodiversity Authority. Chennai, Tamilnadu, India. Pp: 35.

Keinath, A.P., M.A. Cubeta and D.B. Langston, Jr. 2006. Cabbage Diseases: Ecology and Control. Encyclopedia of Pest Management DOI. Taylor and Francis. 
McKellar, M.E., and E.B. Nelson, 2003. CompostInduced Suppression of Pyhthium Damping-off is Mediated by Fatty-Acid-Metabolizing SeedColonizing Mikrobial Communities. Applied and Environemental Microbiology 69(1): 452-460.

Nannipieri, P., J. Ascher, M.T. Ceccherini, L. Landi, G. Pietramellara and G. Renella. 2003. Micronial diversity and soil functions. Europe Journal od Soil Science 54:655-670.

Odum, E.P. 1971. Fundamentals of Ecology. Third Edition. W.B. Saunders Company.Philadelphia, Toronto, London. Toppan Company, Ltd. Tokyo, Japan.

Pirzan, A.M., dan P. R. Pong-Masak. 2008. Hubungan Keragaman Fitoplankton dengan Kualitas Air di Pulau Bauluang, Kabupaten Takalar, Sulawesi Selatan. Biodiversitas, 9 (3) 217-221.

Pitt, J.I. and A.D. Hocking. 1997. Fungi and Food Spoilage. Blackie Avademic and Professional. Second Edition. London-Weinhein-New YorkTokyo-Melboune-Madras.
Rad, J.E., M. Manthey and A. Mataji. 2009. Comparison of Plant Species Diversity with Different Plant Communities in Deciduous Forests. Int. J. Environ. Sci. Tech, 6(3): 389394.

Samson, R.A., E.S. Hoekstra, and C. A.N. Van Oorschot. 1981. Introduction to Food-Borne Fungi. Centraalbureau Voor-Schimmelcultures. Institute of The Royal Netherlands. Academic of Arts and Sciences.

Semangun, H. 1989. Penyakit-penyakit Penting Tanaman Hortikultura di Indonesia. Gadjah Mada Press. Yogyakarta.

Sinh, D.P. and H.B. Singh. 2008. Microbial wealth regulate crop quality and soil health. Knowledge Treasure on ELISA. Departement of Mycology and Plant Pathology, Institute of Agriculture Sciences, Baranas Hindu University, 25-26 p.

Sugiyono, 2009. Statistika untuk Penelitian. Penerbit Alfabeta. Bandung. 